\title{
\#JusticeforGeorgeFloyd:
}

\section{How Instagram Facilitated the 2020 Black Lives Matter Protests}

\author{
Ho-Chun Herbert Chang ${ }^{1,3}$, Allissa V. Richardson ${ }^{1} \&$ Emilio Ferrara ${ }^{1,2,3}$ \\ ${ }^{1}$ USC Annenberg School for Communication and Journalism \\ ${ }^{2}$ USC Department of Computer Science \\ ${ }^{3}$ USC Information Sciences Institute
}

\begin{abstract}
We present and analyze a database of 1.13 million public Instagram posts during the Black Lives Matter protests of 2020, which erupted in response to George Floyd's public murder by police on May 25. Our aim is to understand the growing role of visual media, through a comprehensive view of the spatial (where) and temporal (when) dynamics, the visual and textual content (what), and the user communities (who) that drove the social movement. Using network and time-series analysis, results reveal New York, California, and Minnesota evolved as the epicenters of online social interaction. Our results also make two theoretical contributions. Social movements traditionally typologize posts as discrete instances of mobilization, organization, or conversation. The semantic analysis of 1.69 million photos show these functions are folded together visually. Second, we discuss how pre-existing meme groups and international organizations stood in solidarity to critically assist information dissemination. Together, these analyses demonstrate the precarious nature of protest journalism, and how international content creators, journalists, and everyday users co-evolved with social media to report on one of America's largest-ever human rights movements.
\end{abstract}

Keywords: Black Lives Matter, Instagram, protest journalism, semantic analysis, temporal analysis

\section{Introduction}

On May 25, 2020, a 17-year-old girl named Darnella Frazier used her smartphone to film Minneapolis police officer Derek Chauvin kneeling on the neck of George Floyd for more than nine minutes (Hill et al., 2021). She uploaded the footage of the fatal incident to Facebook . Within two days, the video went viral, sparking global outcry. By June 2, 2020, Brianna Agyemang and Jamila Thomas, two Black women and music executives at Atlantic Records created the viral hashtag \#TheShowMustBePaused (Kaufman, 2020). They called on recording artists to use their platforms to draw attention to systemic racism, by posting a single Black square on their Facebook and Instagram timelines. Millions of everyday people joined the initiative and did the same, in what came to be known as \#BlackOutTuesday (Coscarelli, 2020). 
This study provides a snapshot of the Instagram activity leading up to this viral moment, tracking it through its apex and eventual nadir. Our investigation is novel, insofar, as \#BlackOutTuesday likely marks the first time in the history of social media movements that a visual platform - not a predominantly text-based one like Twitter — took center stage. Twitter has been well-studied since the Arab Spring uprisings of 2011 (Khondker, 2011; Howard and Hussain, 2013; Hermida et al., 2014; Arafa and Armstrong, 2016). Most of these investigations have focused on textual diffusion, however, ignoring the truism that a picture is worth a thousand words. In modern social movements, it is often an incendiary photo or video that galvanizes the public's support for a social justice issue (Marsh, 2018; Edrington and Gallagher, 2019; CorrigallBrown, 2012; Neumayer and Rossi, 2018). These images can seem fleeting, however, because ephemeral platforms such as Instagram feature videos that disappear after 24 hours and an endless scroll of content that can be hard to search. This study, therefore, answers a recent call for media scholars to document more visual social media content for scholarly analysis (Richardson, 2020). The data collection we carried yielded a corpus of almost 1.7 million photos obtained during the June 2020 Black Lives Matter protests. We use these images to explore how platform affordances can shape a social movement's political communication.

Our analysis follows in three parts. First, we explain how (and why) Twitter was invaluable to the first wave of the Black Lives Matter movement, while its second wave belonged to Instagram. Next, we summarize the evolution of Instagram studies, to emphasize further why we chose to highlight this emergent site for protest journalism. Thirdly, we provide an overview of \#BlackOutTuesday's spatial (where) and temporal (when) dynamics; its visual and textual content (what); and its user communities (who) that drove the social activity. Taken together, these analyses demonstrate the precarious nature of movement media, and how content creators, journalists, and everyday Instagram users co-evolved their earlier social media practices to report on one of America's largest-ever human rights movements.

\section{Twitter and the First Wave of Black Lives Matter}

The Black Lives Matter movement began in 2013, when George Zimmerman was acquitted for shooting and killing Trayvon Martin, an unarmed Black teenager, in Florida. Alicia Garza (2014), a well-known political organizer from Oakland, California, wrote a love letter to Black people after the verdict was announced, and posted it on Facebook. She ended it with the sentence, "Black Lives Matter." Her friend and fellow organizer, Patrisse Cullors, added a hashtag to the front of the message, and re-broadcast it on Twitter. It would be one more year before the \#BlackLivesMatter hashtag went viral in 2014. On August 9, a White police officer, Darren Wilson, shot and killed an unarmed Black teenager, Mike Brown, in Ferguson, Missouri. When police allowed Brown's body to lay in the road for four hours, uncovered in the sweltering summer heat, peaceful protests began (Buchanon et al., 2015). Citizen journalists used the hashtag to document Brown's killing and the community's outrage (Lopez, 2016). Activists used the 
\#BlackLivesMatter hashtag to call on the police department to cover up Brown, out of respect for his humanity. For the rest of the summer, use of the hashtag soared (Anderson et al,. 2020).

Groups that opposed the new Black Lives Matter movement created counternarrative hashtags, such as \#AllLivesMatter (to reject claims of racism in policing) and \#BlueLivesMatter (to support law enforcement) (Carney, 2016; Solomon, 2021; Baptiste, 2021). An exhaustive study of Twitter discourse found that six major communities relied on Twitter to discuss police brutality in 2014 and 2015: Black Lives Matter activists, Black entertainers, conservatives, bipartisan reporters, legacy media outlets, and young Black Twitter users. Freelon, McIlwain, and Clark (2016) analyzed 40.8 million tweets, more than 100,000 web links, and 40 interviews with frontline activists and allies, and discovered that the vast majority of those who tweeted using the \#BlackLivesMatter hashtag denounced police brutality. The authors also found that activists who tweeted movement-related news succeeded in educating "casual observers" who either expressed "awe and disbelief at the violent police reactions to the Ferguson protests" or "conservative admissions of police brutality," (p. 1) especially in the cases of Eric Garner and Walter Scott's public police killings. Overall, the research postulated that activists' primary goals using Twitter were "education, amplification of marginalized voices, and structural police reform" (p. 1).

Subsequent inquiries into the Black Lives Matter movement's use of Twitter in 2016 included how users craft counternarratives to anti-Black racism (Richardson, 2020; Jackson, 2016); how Black feminists hijacked the platform to highlight intersectional struggles (Jackson, 2016; Brown et al., 2017); and even how Millennial organizers were departing from the Civil Rights Movement's protest templates to create their own (Clayton, 2018; Ray, 2020; Theoharis, 2016). The Pew Center, for example, reported in 2016 that the \#BlackLivesMatter hashtag peaked during the 10 days spanning July 7-17-with an average of nearly 500,000 tweets of the back-to-back killings of Alton Sterlingaily. Studies such as these centered around Twitter as a digital public sphere (Papacharissi, 2002). In the book Hashtag Activism, for example, the authors argue that the Black Lives Matter movement, and other contemporary Twitter-based movements then, were propelled by strong Twitter communities of Black women. The \#GirlLikeUs transgender justice campaign, or the \#SayHerName movement to raise awareness about Black women victims of police brutality, flourished and thrived on the platform (Jackson, Bailey \& Foucault Welles, 2020). As the decade came to a close, the Black Lives Matter movement waned. Although publications such as The New York Times or The Atlantic published end-of-decade pieces on how social media shaped modern protest in the 2010s, the emphasis remained on Twitter's impact — until this study.

\section{Instagram and the Second Wave of Black Lives Matter}

In May 2020, Darnella Frazier's cellphone video of George Floyd's murder reinvigorated the Black Lives Matter movement - in the same way that the photographs of Emmett Till's 1955 lynching rebooted the dwindling, post-World War II Civil Rights Movement (Hairman and Lucaites, 2016). In Bearing Witness While Black, Richardson draws these parallels, arguing that 
pictures and videos have an outsized role in Black movement-building. Richardson also documents the rise in smartphone video as a tool for political testimony to explain why Black Americans "press record" as a means to fight back against systemic oppression in the US (Richardson, 2020).

Prior to this study, media pundits and scholars explored Instagram's affordances and content, largely outside of the scope of social movement media. In Instagram Power (Miles, 2013), for example, the author focuses on how the platform can be used to commodify images and build strong lifestyle brands. Another early probe into the world of Instagram endeavored to explain how users' "experiences of production, sharing, and interaction with the media they create" are mediated by the "interfaces of particular social media platforms" (Hochman and Manovich, 2013). This study was one of the first to use computational analysis and visualizations to explore Instagram's social and cultural patterns. The team compared the visual signatures of 13 different global cities using 2.3 million Instagram photos, and honed in on 200,000 Instagram photos that were uploaded in Tel Aviv, Israel. While the three-month study confirmed that one could ascertain people's activities and political habits from the geotagged photos, there was not a sustained look at a particular viral moment.

Other Instagram studies from the 2010s followed a similar pattern. Scholars often investigated what images people uploaded to Instagram (Manikonda \& Kambhampati, 2014; Ferrara et al., 2014) or how to detect the age of a user from their photos (Jang, Han, Shih \& Lee, 2015), but stopped short of analyzing Instagram photos during moments of political unrest. Still other studies elucidated the effects of pop culture (Al-Kandari, Al-Hunaiyyan \& Al-Hajri, 2016), or the five primary social and psychological motives of Instagram use: "social interaction, archiving, self-expression, escapism, and peeking" (Lee et. al, 2015). Recent studies on political movements followed en suite. Meme pages, for instance, have been recently characterized to spark instances of political participation in Morocco (Moreno-Almeida 2020), maintain partisan identity in Canada (McKelvey et al. 2020), or even serve as a vehicle for misinformation (Zidani and Moran 2021). Amid the virality of the \#BlackOutTuesday hashtag on Instagram we decided to study the visual platform, finally, in a political context.

The backdrop of the global discourse about Mr. Floyd's controversial video was not the only reason for the shift away from Twitter and toward Instagram. Instagram content is four times more likely to be geotagged than Twitter content, which provides us invaluable insight into when and where the \#BlackOutTuesday groundswell occurred. Our parallel Twitter analyses did not glean rich photo and video data either, since we wanted to know what people posted on the campaign's big day, aside from the black squares of solidarity. Instagram provided the right lens for studying the visual dimension of this phenomenon. Recent studies have also shown the importance of racial presentation in mediating (mis)information dissemination (Freelon et al., 2020). Furthermore, the Twitter discourse we analyzed seemed more like "ambient journalism" (Hermida, 2010) that was always on, rather than the more intentional educational and call-toaction-style posts that we observed casually on Instagram. 
Lastly, we shifted our focus toward Instagram because the people did too. Many of the \#BlackOutTuesday posts on Twitter linked back to an original post on Instagram, using either Facebook's native algorithmic syncing tool or the IFTTT (IfThisThenThat) application. We were also intrigued by Instagram's many technological affordances. The platform remains a walled garden, which does not make it easy for users to hyperlink outward. Trapping captive audiences within Instagram gives the platform enormous power over what the user sees. Without trigger warnings or decency screens over controversial content, Instagram users in June 2020 faced an increased likelihood of viewing potentially harmful content while scrolling through their feeds. Likewise, users found that they were beholden also to Instagram's opaque user guidelines around protest posts. A USA Today piece reported that Black users were suspended from Facebook for even talking about racism (Guynn 2020). Similarly, Instagram and TikTok apologized for algorithmically silencing Black voices (Cortes 2020; Bowenbank 2020).

Our last preoccupation with Instagram during the \#BlackOutTuseday campaign centered around protesters who were captured in the viral pictures. Their visibility meant that their chances of being added to police's facial recognition databases or other forms of AI-based cataloguing grew. Much like the 2019 Anti-Extradition Law protests in Hong Kong — when activists combatted doxxing by communicating through an high-level encryption app, Telegram - we observed users creating 24-hour ephemeral Instagram "Lives" that were designed to disappear, presumably to limit the retrieval of their movement media. Emergent ethical issues such as these inspired the following research questions:

1. What were the temporal characteristics of June 2020's second wave of the Black Lives Matter movement, in terms of frequency, geography, and textual content?

2. What were the top images on Instagram, and how can we typologize semantic meaning?

3. Who were the central actors and communities that emerged on Instagram on \#BlackOutTuesday?

\section{Methods}

\section{Data Collection and Description}

We monitored Instagram posts for \#JusticeForGeorgeFloyd from May 28, 2020 to June 31, 2020, extracting the top shortcodes from the public hashtag page. These posts were then extracted using their static short codes, including all photos, videos, post-specific public metadata, and comments. No personal information was collected, and non-verified accounts were hashed.

\section{Table 1}

Description of scraped data, including metadata, photos, and videos. 


\begin{tabular}{|l|l|}
\hline Data Type & Sample size \\
\hline Posts/descriptions & $1,147,278$ \\
\hline Photos & $1,694,909$ \\
\hline
\end{tabular}

Exactly 155,282 of 1.13 million culled posts (13.7\%) have location tags. This is a significantly higher rate of geotagging than one might find in a Twitter dataset, which typically averages 3\% geotagged posts (Ferrara et al, 2020). We posit this arises due to the visual, scrapbook nature of the platform, as every picture taken live is associated with a physical location. The inclusion of this metadata allows us to understand the flow of protest geographically with a much higher statistical power. Importantly, this included not just the United States but multiple countries.

Table 2 shows the total number of posts by state, as an overview of the distribution of participation throughout the US. While California, Florida, New York, and Texas occupy top positions as expected due to their large population, Minnesota is significant since the movement originated from there. Washington, DC generated a high level of participation as well.

\section{Table 2}

Top states by number of posts and comparison with population.

\begin{tabular}{|l|r|r|r|r|}
\hline State & Num. of Posts & Prop. of posts & Rank by Population & \multicolumn{1}{l|}{ Prop.by Pop. } \\
\hline CA & 32,705 & 0.210617 & 1 & $11.91 \%$ \\
\hline NY & 23,477 & 0.151189 & 4 & $5.86 \%$ \\
\hline MN & 14,935 & 0.09618 & 22 & $1.70 \%$ \\
\hline TX & 10,212 & 0.065764 & 2 & $8.74 \%$ \\
\hline FL & 7,501 & 0.048306 & 3 & $6.47 \%$ \\
\hline DC & 6,573 & 0.042329 & 49 & $0.21 \%$ \\
\hline GA & 6,506 & 0.041898 & 8 & $3.20 \%$ \\
\hline IL & 4,704 & 0.030293 & 5 & $3.86 \%$ \\
\hline PA & 4,685 & 0.030171 & 6 & $3.82 \%$ \\
\hline OR & 3,068 & 0.019758 & 27 & $1.27 \%$ \\
\hline
\end{tabular}


To discern the discursive dimension of the protest shown, we collected the top hashtags and sorted them by usage in Table 3. The top hashtags includes different iterations of support for George Floyd (such as \#JusticeForGeorgeFloyd and \#GeorgeFloyd) and reference to the Black Lives Matter movement (\#blm and \#blacklivesmatter). The phrase \#icantbreathe also emerged as an important hashtag, co-occuring in $10 \%$ of all posts.

\section{Table 3}

Top hashtags with a total of 540,591 unique hashtags.

$\begin{array}{rrrr}\text { hashtag } & \text { counts } & \text { hashtag } & \text { counts } \\ \text { justiceforgeorgefloyd } & 1,025,048 & \text { minneapolis } & 43,066 \\ \text { blacklivesmatter } & 719,046 & \text { equality } & 42,539 \\ \text { georgefloyd } & 301,076 & \text { stopracism } & 38,684 \\ \text { blm } & 224,415 & \text { peace } & 37,484 \\ \text { blackouttuesday } & 198,372 & \text { breonnataylor } & 36,603 \\ \text { justiceforbreonnataylor } & 156,208 & \text { black } & 35,466 \\ \text { justiceforahmaud } & 144,287 & \text { repost } & 34,324 \\ \text { icantbreathe } & 126,407 & \text { allivesmatter } & 32,894 \\ \text { justiceforfloyd } & 122,818 & \text { saytheirnames } & 32,607 \\ \text { nojusticenopeace } & 114,406 & \text { blackoutday2020 } & 31,062 \\ \text { justice } & 109,319 & \text { justiceforahmaudarbery } & 30,918 \\ \text { protest } & 85,273 & \text { ahmaudarbery } & 28,020 \\ \text { policebrutality } & 61,884 & \text { acab } & 27,212 \\ \text { racism } & 54,935 & \text { usa } & 26,973 \\ \text { love } & 53,351 & \text { endracism } & 26,849\end{array}$

Moreover, the important feature of this second-wave Black Lives Matter movement was that it demanded legal and moral justice for other people who died from white supremacist vigilantism and police brutality around the same time as Mr. Floyd. Dual campaigns for Ahmaud Arbery (who was killed by three White men in Georgia that spring while jogging) and Breonna 
Taylor (whom police killed in Indiana after issuing a mistaken no-knock warrant to her home) also emerged. The \#saytheirnames hashtag attempted to connect these cases.

Interestingly, the \#JusticeForGeorgeFloyd hashtags occurred prior to his death. A quick survey indicated these hashtags were added retroactively to posts to generate attention and traffic, what scholars might refer to as the pursuit of clout. These posts were filtered out.

\section{Visual Content Analysis through Perceptual Hashing}

To determine the top visual content that emerged from the movement, we first identified similar figures by conducting a perceptual hash (phash) on each image. This converts each picture into a 64-bit string, which is then used to extract the similarity between photos and identify the most popular images based on its hashes (Zauner, 2010). Briefly, the algorithm works by first reducing an image (usually to $32 \times 32$ pixels), converted to greyscale, cosine transformed, then converted to a string. This yields the resultant phash.

\section{Network Analysis}

We then constructed an interaction network using the full set of Instagram comments. A network is a set of nodes, which are connected by a set of edges. Edges can be directed or undirected. Directed nodes indicate a directional relationship (such as unreciprocated following relations on Twitter) or undirected (such as friendships on Facebook). In our analysis, direct edges are constructed between Instagram posters (source node) and people who comment (destination node). Additionally, associated with each edge is a weight - the frequency of times two users interact in the comments section. As Figure 1 shows, there are users who interact hundreds of times within their comments in such a short timespan of 30 days. This resulting network contains $3,337,890$ unique users and 3,976,914 unique edges.

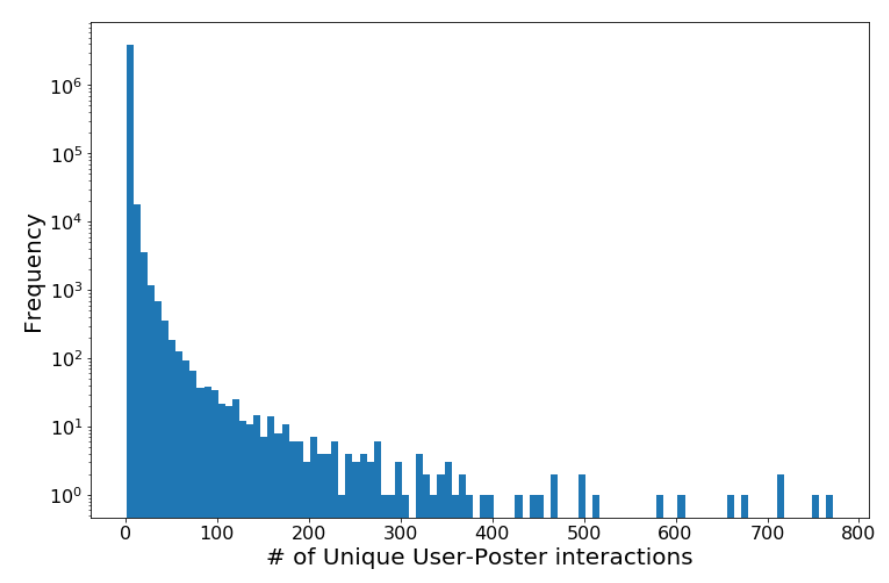

Figure 1: Frequency of Pairwise Interactions 
We then aggregated these networks into state-level networks, to better understand how communication flowed inside and outside local communities. We describe this formally below. Let $U$ denote the set of users and $S$ represent the set of States. $A$ represented the adjacency matrix for users (columns) and States (rows). Our goal was to aggregate $A$ into a State-level adjacency matrix. Let $i$ be the row index and $j$ be the column index ( $a_{i, j}$ the element). The algorithm for generating the state-state network can then be summarized in Algorithm 1.

\section{Algorithm 1}

Method for creating state-state adjacency matrix

$A=$ Adjacency matrix with dimensions $|U| \times|S|$

$A_{S}=$ Pre-allocated $|S| \times|S|$ matrix

for i, state in enumerate $(\mathrm{S})$ :

$$
\begin{aligned}
& E:=\left[v_{j}\right] \quad \forall j \text { s.t. } a_{i, j}>0, v_{j} \text { is the column vector } \\
& A_{S}[i, *]=\left[\sum_{j \in E} v_{j}\right]^{T}
\end{aligned}
$$

In simple terms, for each user (represented by a column), we considered all the geographical sources to which the user had been exposed. For example, if a user had engaged with a post from both New York (NY) and Minnesota (MN), then the incoming edge from MN to NY (denoted $\mathrm{MN} \rightarrow \mathrm{NY}$ ) would be equivalent to the number of times the user engaged with content from MN. Vice versa, $\mathrm{NY} \rightarrow \mathrm{MN}$ denotes the number of times the user engaged with posts from NY. The user serves as a proxy for cross-engagement between states. Thus, the aggregation of all user-state aggregations is the total weight between two states.

We also share a brief note comparing how Instagram and Twitter networks are constructed. Since Instagram does not allow the sharing of URLs and hyperlinks, exposure to a post is strictly mediated by Instagram's algorithm. As such, there is no direct equivalent of a retweet. Commenting on Instagram is equivalent to replying on Twitter, and this restricted form of networking naturally impacted the topology of the Instagram network.

\section{Results}

RQ1: What were the temporal characteristics of June 2020's second wave of the Black Lives Matter movement, in terms of frequency, geography, and textual content?

To address this question, we considered the frequency of posts over the month of protest. Figure 2 shows the distribution of post frequencies on an hourly basis between May 25, 2020 and June 25, 2020, on a log-basis. Right after the killing of George Floyd on May 25, we observed a lull of activity. This was punctuated then by an increase on May 31. This remained consistent until 
exploding in volume on June 3. Its use then decayed exponentially (from the order of 10,000 to 1,000 in two days).

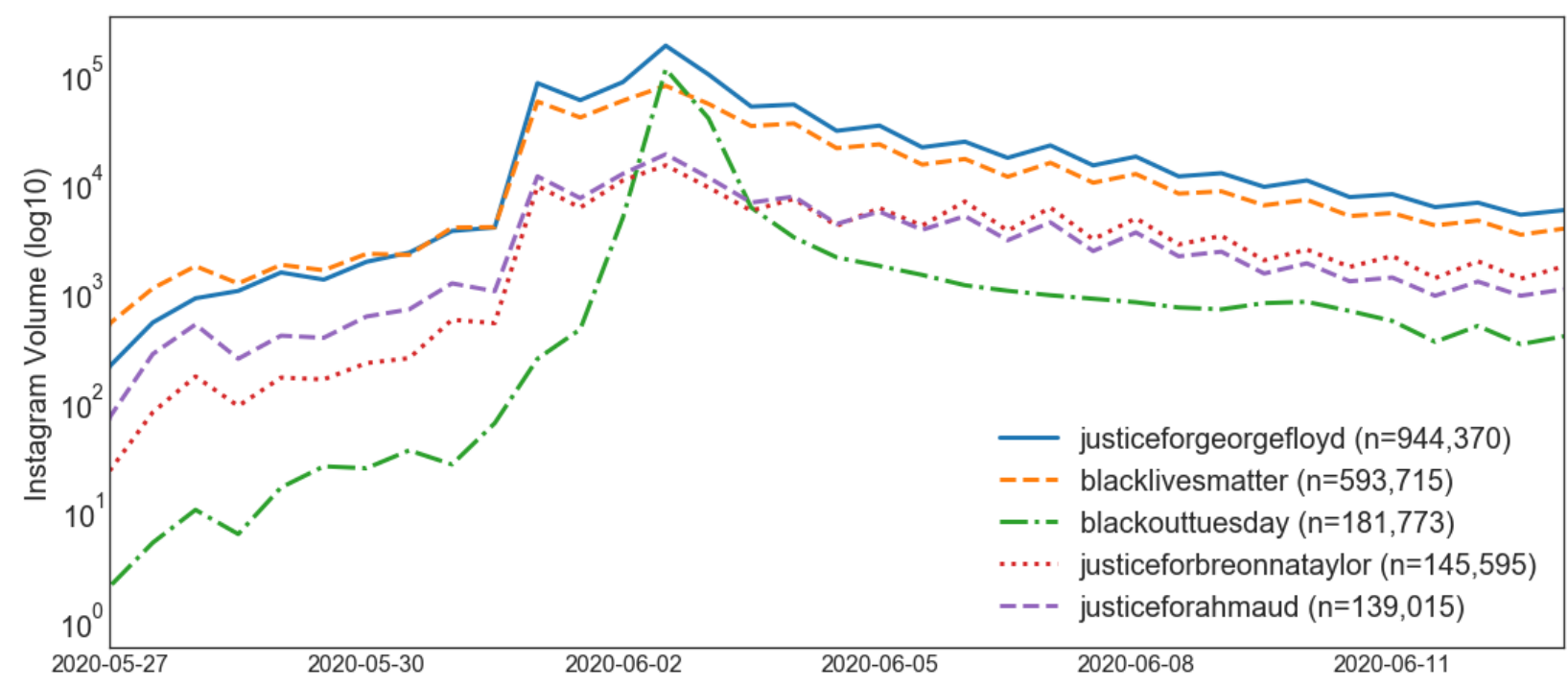

Figure 2: Volume of Instagram posts plotted on an hourly basis, separated by top hashtags shared during the George Floyd Protests.

Figure 2 also shows the top hashtags shared during the month of protest and give clues to what generated the spikes on May 31 and June 3. Hashtags can be summarized as a few distinct categories: 1) mentions of George Floyd, Breonna Taylor, and Ahmaud Arbery, and 2) the BLM movement and the slogan \#icantbreathe. The one exception is \#BlackOutTuesday. It was localized during the spike on June 1, which suggests that the industry-led movement was not just a critical driver of momentum, but the most viral event on social media between May 30 and June 3. We can thus split the second wave of the Black Lives Matter movement into two periods: the first, driven organically after the death of George Floyd, and the second, driven purposefully via \#BlackOutTuesday event.

Figure 3 shows the most popular times of digital protest temporally and geographically. Figure 2a) shows these times converted to EST. We observe a few peaks - at 11PM, 3PM, 9PM and 3PM. Overall, there seems to be a superimposition of two time zones. Figures $3 \mathrm{~b}$ ) shows this more clearly through its geographic distribution, using June 3 as an example as it contained the highest amount of digital activity. We observe the most activity emerging in New York, California, Texas and Minnesota beginning at 11AM when adjusted for time zones. Temporal trends are consistent with event-driven social movements, such as Occupy Wall Street and Turkey's Gezi Park Protests (Conover et al., 2013; Varol et al., 2014). 

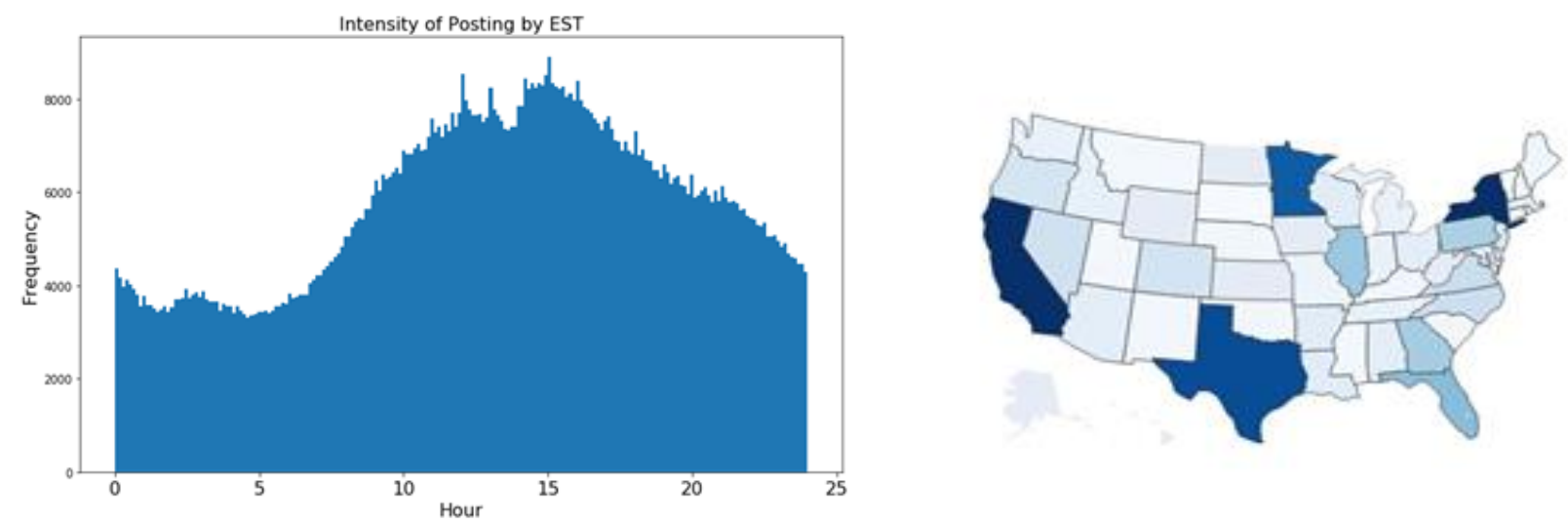

Figure 3: Frequency of posts adjusted for time zone. Figure 3a) shows the frequency of posts in EST. Figure 3b) shows the tweet volume between 03:00PM and 04:00PM EST.

\section{Geographic Network Analysis}

We turn our attention to the interaction between States, summarized in Table 4. The summary technique follows network flow based on the direction of edges (Chang et al., 2021). Immediately, we noticed a high percentage within several states, with South Dakota at 0.805 and Vermont at 0.688. California had the highest frequency of posts at 0.617 (rank 4) and Minnesota at 0.589 (rank 6). We reached two conclusions. For states with high levels of participation (CA and $\mathrm{MN}$ ), we observe high levels of self-generated content within the state. For states with smaller volumes of participation, users are more isolated and engaged more with local activism.

We contrasted this to States with comparatively high levels of content "exports" and "imports." What we mean by exports is the proportion of posts engaged by users connected to other States. What we mean by imports is the proportion of posts users engaged with that hailed from other States. Washington, DC is the highest importer, indicating the region had limited amounts of self-generated content. New York was a top importer too, yet boasted very high levels of engagement within its own State still, indicating high levels of participation.

\section{Table 4}

Interstate network structure and proportion of posts seen within-state, exported to other states, and imported from other states.

\begin{tabular}{|l|r|r|r|r|}
\hline \multicolumn{5}{|c|}{ Top Self-Content } \\
\hline State & \% within State & \% exported & \% imported & Total posts from state \\
\hline SD & 0.805 & 0.112 & 0.083 & 447 \\
\hline VT & 0.688 & 0.181 & 0.131 & 474 \\
\hline
\end{tabular}




\begin{tabular}{|l|r|r|r|r|} 
& & & & \\
ID & 0.643 & 0.202 & 0.156 & 1,760 \\
\hline CA & 0.617 & 0.156 & 0.227 & 358,948 \\
\hline WY & 0.603 & 0.212 & 0.184 & 179 \\
\hline MN & 0.589 & 0.199 & 0.212 & 158,753 \\
\hline FL & 0.581 & 0.213 & 0.206 & 101,843 \\
\hline
\end{tabular}

\begin{tabular}{|c|c|c|c|c|}
\hline \multicolumn{5}{|c|}{ Top exporters } \\
\hline State & $\%$ within State & $\%$ exported & $\%$ imported & Total posts from state \\
\hline WV & 0.246 & 0.600 & 0.154 & 965 \\
\hline $\mathrm{NE}$ & 0.362 & 0.495 & 0.142 & 1,968 \\
\hline ND & 0.348 & 0.474 & 0.177 & 603 \\
\hline $\mathrm{NH}$ & 0.368 & 0.436 & 0.196 & 1,471 \\
\hline MS & 0.311 & 0.430 & 0.259 & 2,495 \\
\hline
\end{tabular}

\begin{tabular}{|l|r|r|r|r|}
\hline \multicolumn{7}{|c|}{ Top Importers } \\
\hline State & \% within State & \% exported & \% imported & Total posts from state \\
\hline DC & 0.433 & 0.279 & 0.289 & 83,710 \\
\hline MD & 0.422 & 0.293 & 0.286 & 20,912 \\
\hline IA & 0.327 & 0.394 & 0.279 & 3,052 \\
\hline NY & 0.548 & 0.180 & 0.272 & 268,169 \\
\hline MI & 0.391 & 0.347 & 0.262 & 19,452 \\
\hline
\end{tabular}

Apart from Mississippi engaging with content primarily from Texas, every other state engaged primarily with posts from either New York or California. We show these dependencies further in Figure 4, which shows its aggregated top co-occurence of locations based on all user engagement. We observe the emergence of three epicenters: California, New York, and Minnesota. California received the most content from New York and, reciprocally, New York from California. New York seemed to hold the attention of East Coast states close by, such as New Jersey, Maine, Rhode Island, and Connecticut, along with states from the South that are also closer to the East Coast, such as West Virginia. The rest of the states, with the exception of Mississippi, co-occurred most frequently with California. California demanded the attention of Minnesota, and all West coast states most commonly. Mississippi co-occurred most frequently with Texas. 


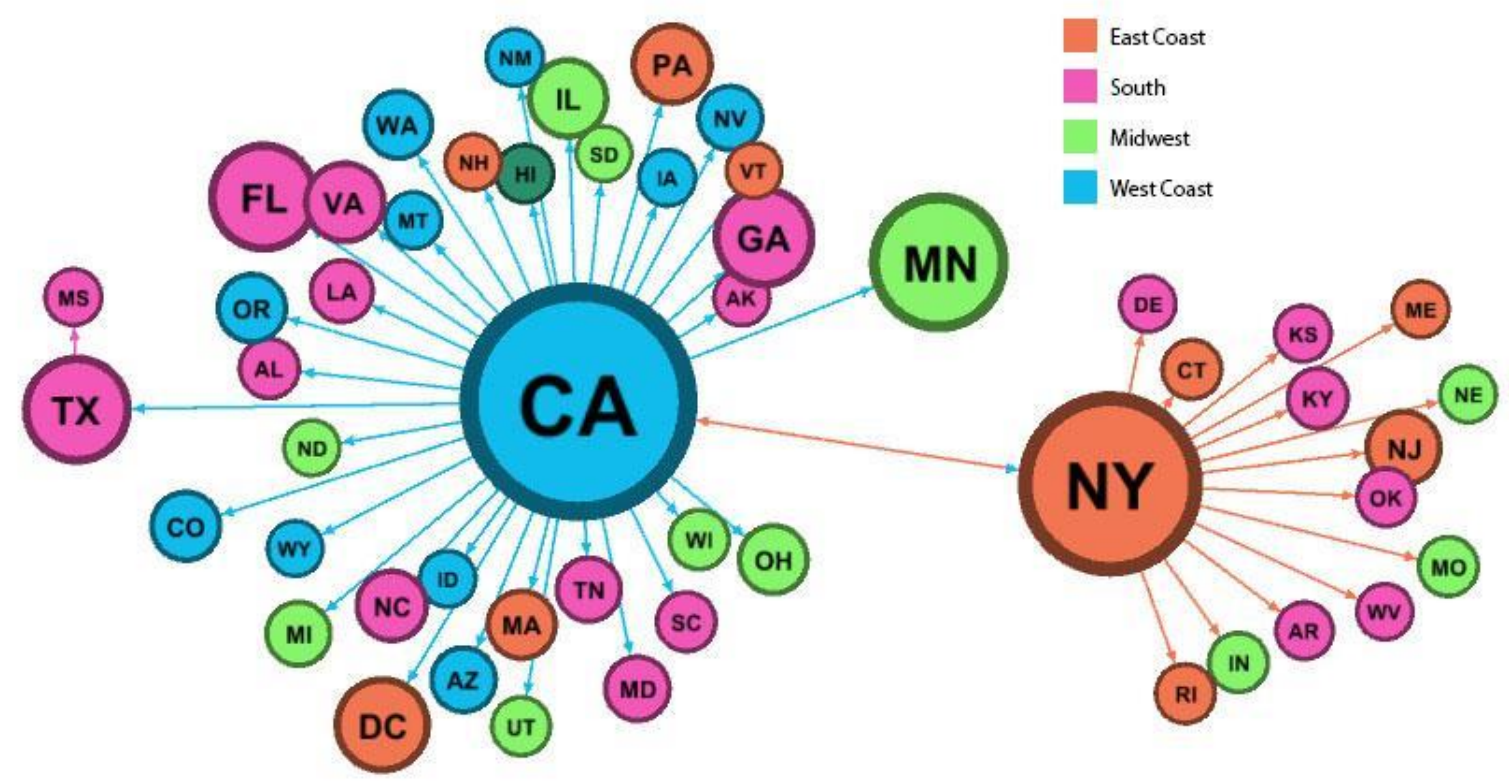

Figure 4: Network of state-state exposure based on aggregated user engagement. The top mutual source of information by geography is shown, colored by general regions in the United States.

This bears similarities with prior studies on US-based social movements. During Occupy Wall Street, Conover et al. (2013) observed a similar hub-spoke structure on Twitter, although in that case activity was localized in California, New York, and Washington DC. Furthermore, the geo-local "trend-setting" phenomenon had been observed on a macroscale, for which similar distributions of activity emerge (Ferrara, 2013). From this analysis, we drew a few conclusions. First, two epicenters of the second wave were California on the West Coast and New York on the East Coast. Minnesota generated high levels of activity within the state itself. The relatively high levels of content within Minnesota suggested localized participation. This mirrored the trends observed in New York, where users in nearby states interacted most with its users. The timeseries also suggested two waves, one beginning on May 29, and the second on June 3.

Now that we have established the when and where, and have answered RQ1, we analyze the specific content that drove the movement forward.

RQ2: What were the top images on Instagram, and how can we typologize their semantic meaning?

\section{Visual Content Analysis}

Figure 6 shows the most shared photos during the month of protest. We see a few themes, which we used to construct a typology. The most popular photo during the period we observed was the \#BlackOutTuesday full black square. The second type of popular posts were iterations of George Floyd's portrait. There are three forms that emerged. The first is his original selfie (GF original), a stenciled style (GF portrait), and a floral version in remembrance (GF floral). 

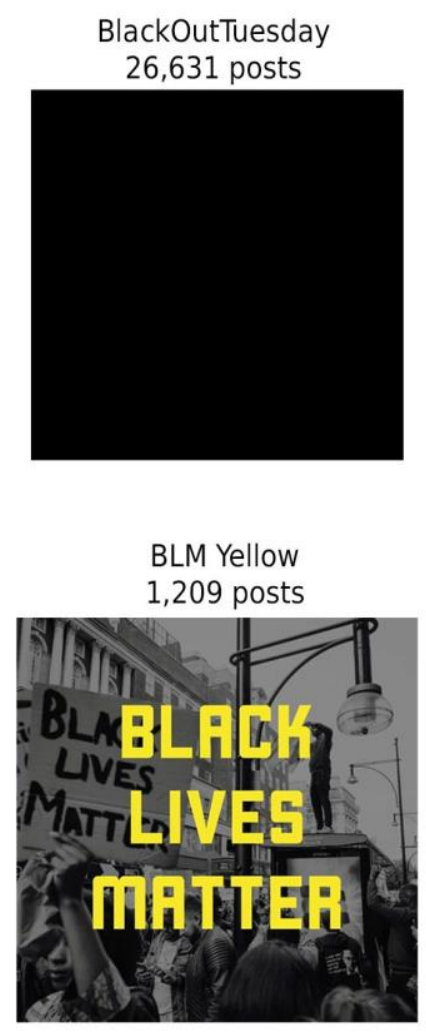

GF Original

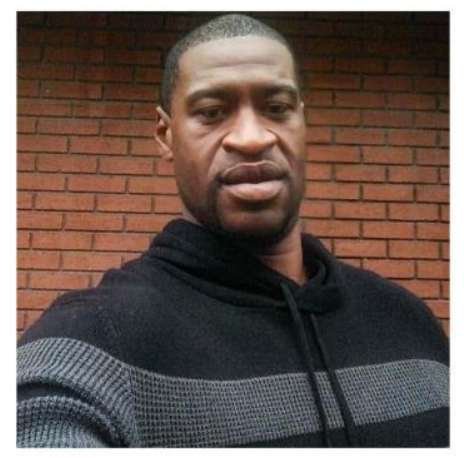

BLM Greyscale 3,043 posts

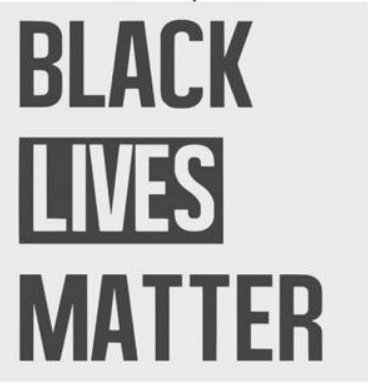

GF Portrait 429 posts

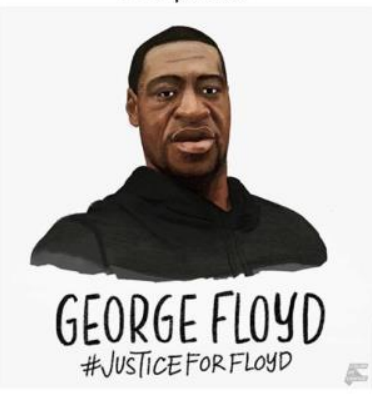

Protest Photography

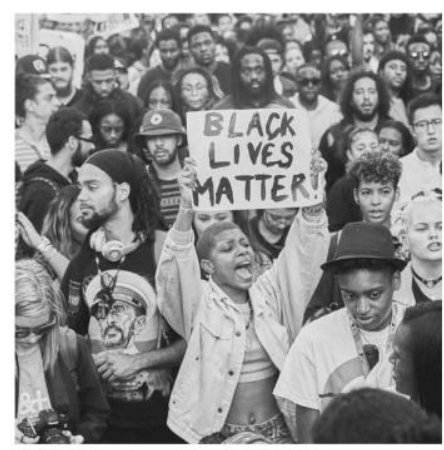

GF Floral

824 posts

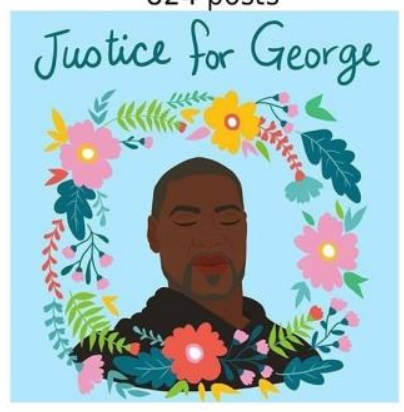

Funding Info 366 posts

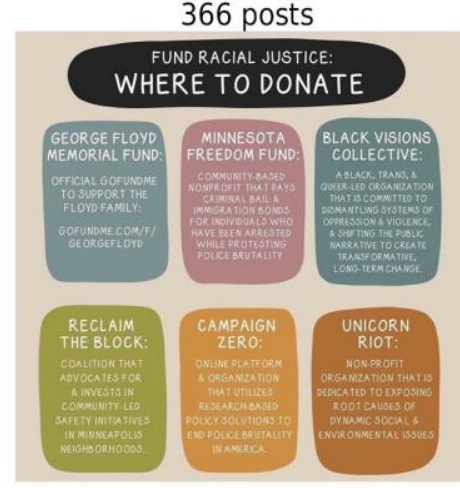

BLM Raised Fist

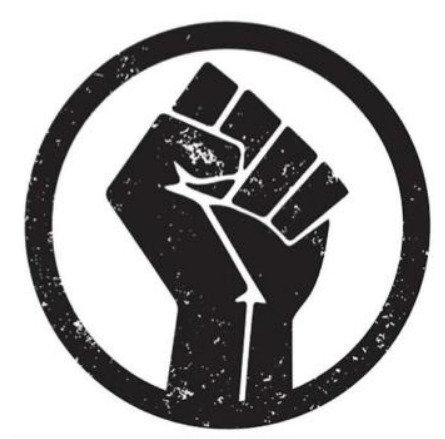

Figure 6: Top photos that emerged from the 2020 George Floyd protests. From top to bottom and left to right, we have the Black Out Tuesday Square (a), logos and icons of the Black Lives Matter movement (b, d, i), portraits of George Floyd (c, e, g), and photos of protest (h).

The third type of common posts were official logos for the BLM movement, which we denoted as BLM grayscale and BLM yellow. The fourth type of common posts were the edited pictures of protest, such as the one in the bottom center. These were prevalent further down the top photos list, however, and not as concentrated in use as the other examples. Lastly, the fifth common post type focused on information sharing and organizing, such as the infographic found in the center left. This infographic contains six places to donate money, such as foundations, bail for protestors, or medical fees for those harmed during the protests. These visuals seem consistent 
with prior theories of connective action and the typologies of content. Theocharis, Lowe, Van Deth, \& García-Albacete (2015) have proposed four types of posts on Twitter: (1) political mobilization; (2) coordination; (3) information; and (4) conversation. It is difficult to categorize some of these posts neatly into one of these four categories. The \#BlackOutTuesday square is certainly an explicit call for action: both digital action and for generating mass in protest. The George Floyd portrait, however, can be seen also as a form of political mobilization, information, and conversation. The time period matters as well. Early forms of George Floyd's portrait were more targeted toward information sharing, whereas latter ones were for conversation. The BLM logos were part of a larger conversation, but also represented a call for political mobilization. The only photo that had a singular categorization was that of the six funding sources.

Unlike Tweets - where the classification relies on explicit textual semantic informationthe four-pronged typology cannot be applied neatly to images, since the categorization depends more on how it is used (the coordinating flooding on Instagram) and its actual contents (as part of a broader piece of social justice discourse). This brings us to the main rationale of our study. When studying social movements, researchers often characterize these movements solely on textual content, given its availability, in absence of other modalities. The use of photos and visual communication evidences that the intent behind coordination may subsume that actual content itself. A portrait is, after all, just a portrait. It is only when disseminated en masse that it becomes meaningful.

We can observe further resonance with existing theories of connective action by considering how these icons diffused over time. Figure 7 shows the BLM logos, the full black squares of \#BlackOutTuesday, and the funding source. Before May 31, there was little volume from the BLM logos, until the grayscale logo exploded in volume-along with information about funding. This indicates some form of coordination (whether organic or pre-determined), as these were observed on an hourly basis. Then, on June 2, (the day of \#BlackOutTuesday), a massive eruption of posts emerged. We observed these beginning as early as midday on June 1, yet the small notch in the black line right before June 2 suggested that users waited for the actual campaign day before posting.

Figure 7b) shows the permutations of the portraits of George Floyd. Notably, the sharing of these photos began much earlier than the BLM logos. The first post that emerged at scale was the realististic portrait, rather than his selfie or the stylized, floral version of him. Then, on the night of May 31, there was a great acceleration of his floral portrait. The popularity of his floral portrait, designed in remembrance rather than simple outrage, became the most popular icon involving him as a person. We note a similar style of portraits were made for Breonna Taylor, and posit people seems more comfortable sharing artwork rather than pictures of the deceased. Both of these points warrant further research. 
a) Logos and Information Sharing

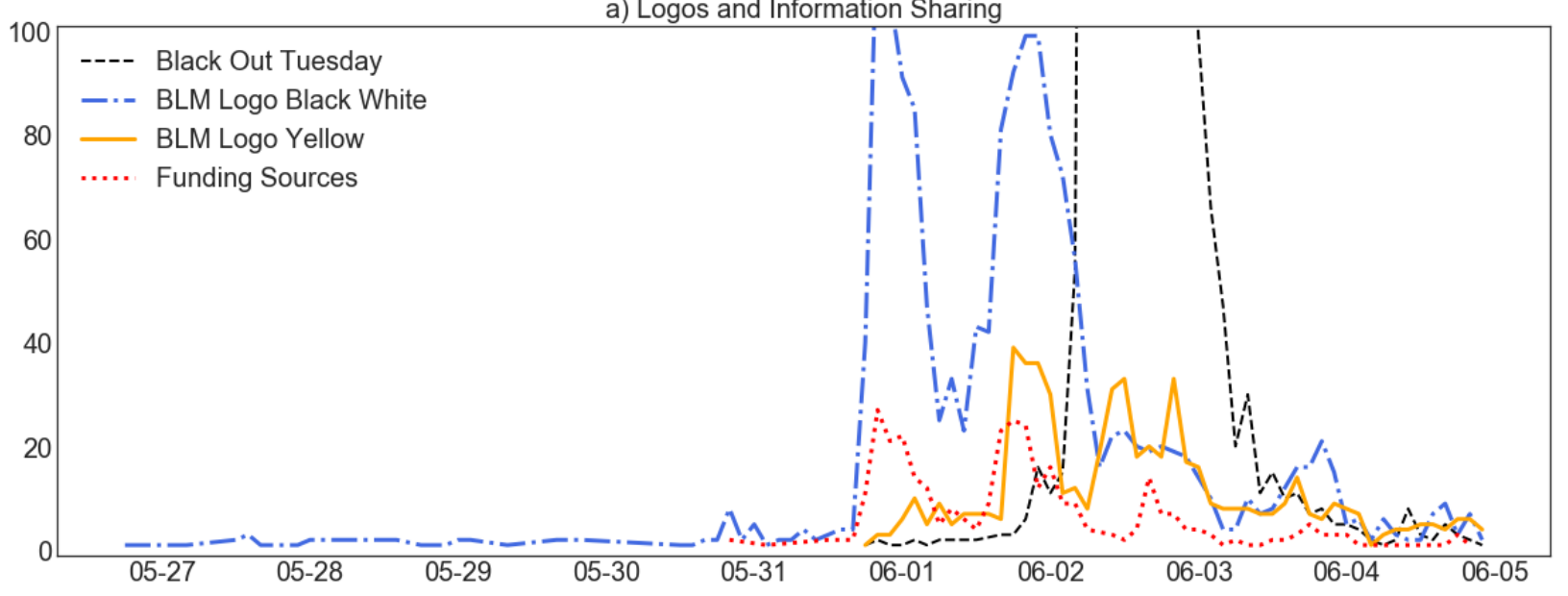

b) Permutations of Floyd Portraits

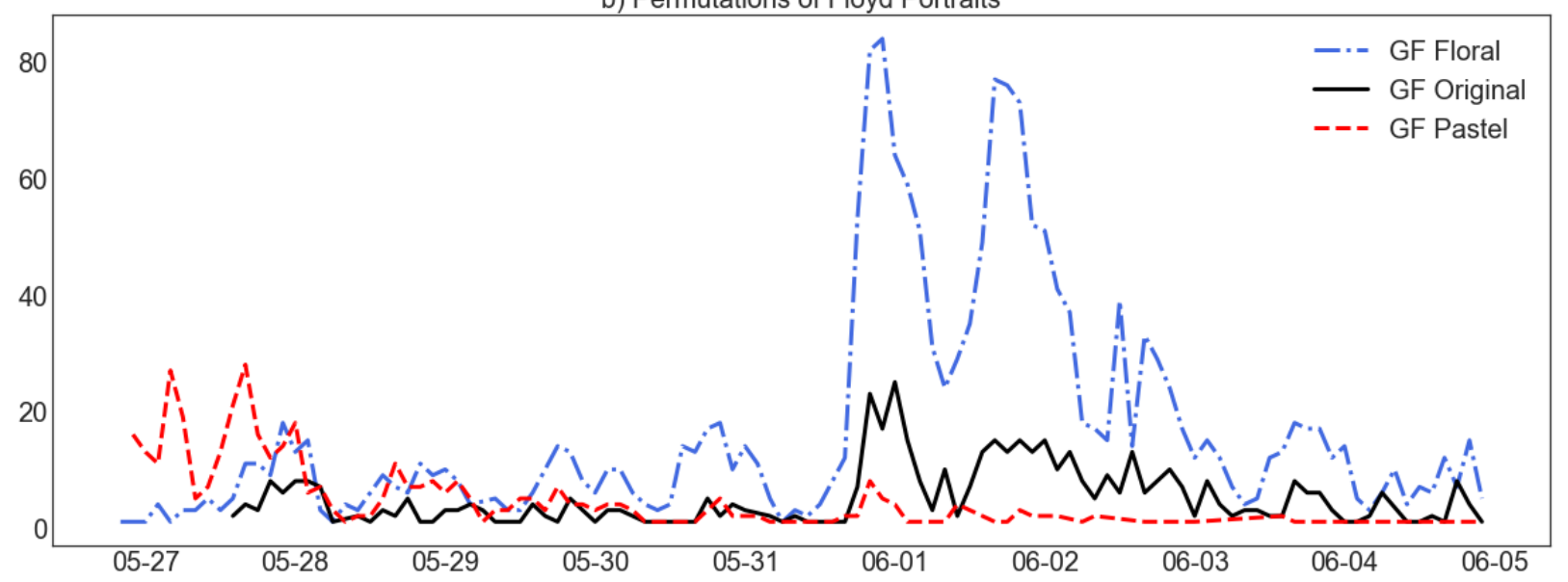

Figure 7: Time series of top icons diffused during the George Floyd protests. Figure 6a) shows the diffusion of the three BLM logos and the funding infographic. Figure 6b) shows the three iterations of George Floyd's portrait. We observe much earlier volume in the portraits as compared to BLM and protest organizations.

This graph is remarkable in a few ways. First, by comparing panels a) and b), we observe an early focus on George Floyd as an individual, as there was volume for his portrait rendered early on, but not much presence of Black Lives Matter logos until late May 31. However, it was only until the inclusion of Black Lives Matter logos when the movement achieved critical mass. In this regard, we make an important temporal observation---the death of individual Black Men becomes the centerpoint that coalesce into a larger movement.

RQ3: Who were the central actors and communities that emerged on Instagram on \#BlackOutTuesday?

We have shown the visual content, the temporal dynamics, and the state-level spatial distribution of the movement. Our next step was to consider the who: Who and which communities 
generated the highest amounts of attention? Table 5 aggregates the top 10 accounts by the number of likes.

Table 5

Top 10 accounts by likes in the dataset

\begin{tabular}{|l|l|l|l|}
\hline Username & Likes & Name & Account Description / Occupation \\
\hline theshaderoom & $7,849,147$ & The Shade Room & $\begin{array}{l}\text { Publication of celebrity gossip } \\
\text { predominantly within the Black } \\
\text { community }\end{array}$ \\
\hline stak5_ & $6,405,100$ & Stephen Jackson, Sr. & Former NBA player \\
\hline midianinja & $3,741,410$ & Mídia NINJA & $\begin{array}{l}\text { Independent narratives and journalism } \\
\text { based in Brazil }\end{array}$ \\
\hline the_female_lead & $2,611,844$ & The Female Lead & Account of an education charity \\
\hline iamjamiefoxx & $2,191,800$ & Jamie Foxx & African-American actor \\
\hline thedisappointingexperie \\
nce
\end{tabular}

What is most interesting about these top users is that their differences largely outweigh their similarities. We take an in-depth look at a few of these specifically to understand why they achieved prominence. The top-ranked user is The Shade Room, an online publication that specializes in celebrity gossip specifically within the Black community. It is worth taking a moment to discuss entertainment-based groups, specifically the growing phenomenon of meme- 
related pages. Included examples are thedisappointingexperience, which puts out a large volume of posts (with a max of 20k likes), and tenth-ranked DomisLiveNews, which combines world news in a meme format, often with a hyper-focus on trivial events such as a Black rapper changing into a pair of new Yeezy sneakers. Their presence on the list is likely due to their large, pre-existing audience base.

Surprisingly, there are only a few individuals in comparison to the organizations. We observed a former NBA player (Stephen Jackson Jr.), an actor (Jamie Foxx), an activist/writer (Shaun King), and a photographer (Gentleman Modern). Apart from King, most of these users are celebrities that have a high follower count. The photographer was the one exception. His prominence can be attributed to his viral post $\mathrm{t}^{\mathrm{i}}$, of two children (one white and one Black) running toward each other and hugging. This lone video garnered more than 1.5 million likes. What this shows is that Instagram's platform algorithms push the content of lesser-known users to the forefront of a movement, just as it amplifies existing influencers.

Apart from these entertainment-oriented groups, we observed solidarity also from other social justice-oriented organizations. Examples include The Female Lead, Diet Prada, and midianinja. The Female Lead is a well-known education charity that focuses on gender-based social issues. Diet Prada is a fashion-related watchdog organization that began from the work of two fashion industry professionals, and grew into a significant voice in critiquing its business practices. They are most well-known, for example, for identifying Dolce \& Gabbana's racist ad in Shanghai which features an Asian man struggling to eat Italian food with a chopstick.

Lastly, midianinja deserves its own separate mention for multiple reasons. First, based in Brazil, its website and content is almost completely in Portuguese. Instead of being an individual, or an organization with a specific intent, they focused rather on a theme. The following excerpt appears on their website:

A partir da lógica colaborativa de produção que emerge da sociedade em rede, conectamos jornalistas, fotógrafos, videomakers, designers, e possibilitamos a troca de conhecimento entre os envolvidos. Based on the collaborative logic of production that emerges from the networked society, we connect journalists, photographers, videographers, designers, and enable the exchange of knowledge between those involved (translated).

The fact that a non-American entity ranked in the upper-third percentile of influencers we observed speaks not only to the global reach of the movement, but also to the role that international organizations took in collaborating with US-based journalists and photographers. Groups like this have evolved alongside social media to spread awareness indeed.

We close this section with a broad overview of the Instagram public sphere. Figure 8 shows the Instagram network. Users are nodes, and a directed edge is drawn when a user comments on the post of another user. The listed users are the top users by in-degree, meaning ones whose posts 
featured the most interaction via commenting. The top users are associated with a certain amount of white-space. This corresponds roughly to the amount of influence- or the amount of commenting interactions - that they elicited from other users. This is a result of tuning parameters from ForceAtlas2, the force-based network layout algorithm used (Jacomy et al., 2014).

The most important qualitative observation is the large number of everyday users located in the middle. This indicates a diverse diet from a central core of users, driven by everyday users. Users are also colored by the state for which they consumed the most content. The graph appears heterogeneous, which is a testament for the national-level of reach.

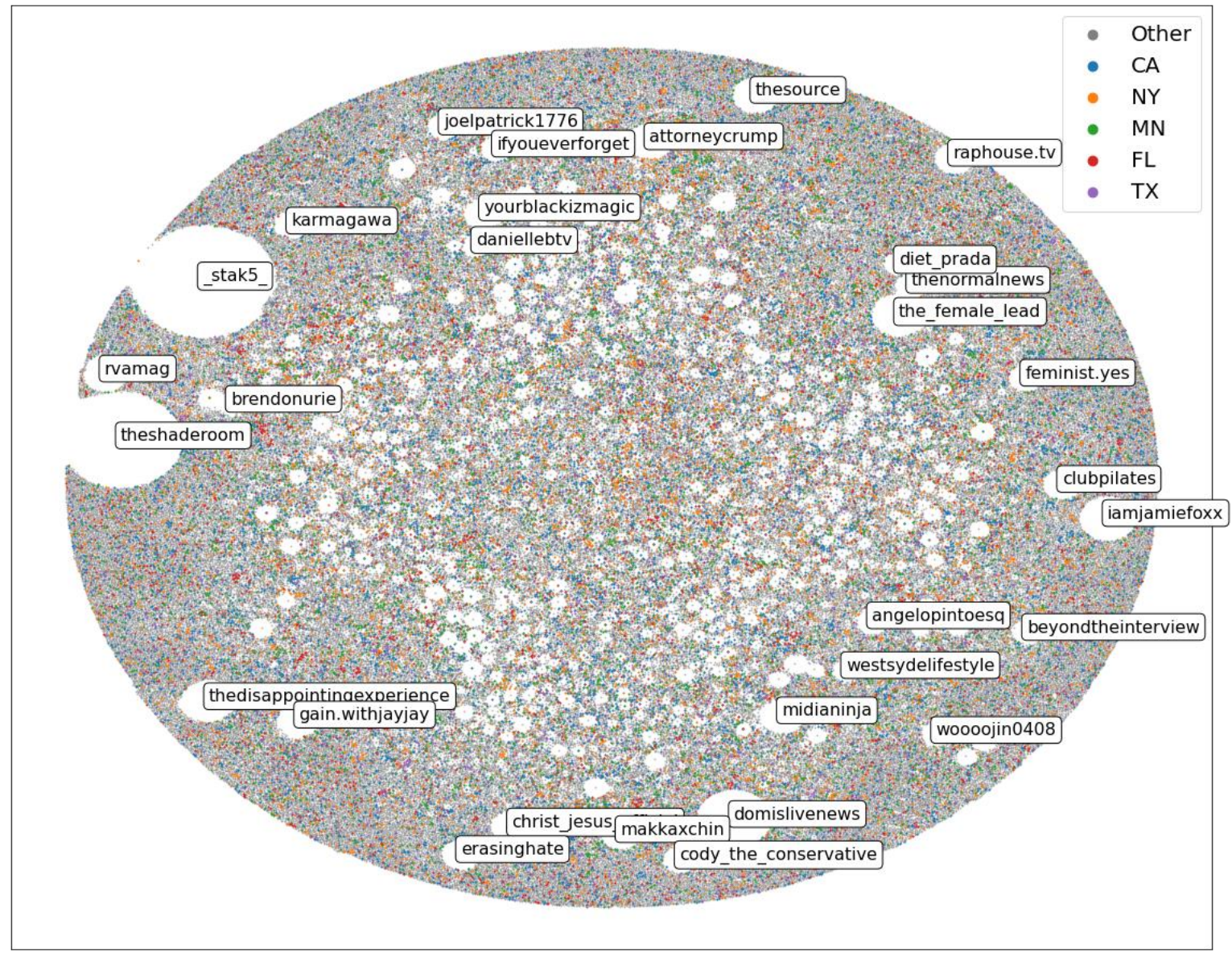

Figure 8: Network of users $(\mathrm{n}=713,209)$, where links are constructed between commenting users and the original poster.

To summarize our answer to RQ3, the most prominent users are existing Black audienceserving publications, individuals, social justice organizations, and meme groups. And unlike Twitter, for which individuals' accounts garner more attention, groups that specialize in content production with an existing audience base seemed to generate the most engagement during the period we observed. 


\section{Conclusion}

The purpose of this study was to understand how Instagram mediated the second wave of the Black Lives Matter protests in 2020. We analyzed the movement across the spatial, temporal, semantic (both visual and textual), and communal dimensions. Spatially, three epicenters arose, with content being consumed most from New York, California, and Minnesota. Mississippi was an outlier, and conversed most frequently with Texas.

Next, we identified three temporal periods of the Black Lives Matter movement's second wave in the summer of 2020. The first, latent phase arose from the sharing of George Floyd's portrait. The second phase began with the explicit mobilization with BLM. The third phase, which generated the largest level of engagement, was from the \#BlackOutTuesday campaign. These two later phases reflect a temporal pattern where individual deaths of African American men become the galvanizing point for the larger Black Lives Matter movement.

The more interesting connections with theory emerged when we studied the visual content. We identified five types of posts: (1) portraits of George Floyd, (2) BLM logos, (3) protest activism, (4) organizational infographics, and (5) the \#BlackOutTuesday square. We observed that this slightly resembles Theocharis' characterizations of posts in times of protest (mobilization, conversation, and organization), but resists a stable definition (Theocharis, 2015). For instance, the portrait of George Floyd's use began as the spread of news, before evolving to serve as a means of remembrance for a larger national discourse. The effect of its flooding was also a call to action. We see these changes both stylistically in the art and in their patterns of diffusion.

In analyzing the top users and the overall network structure, we found users in general were geographically dispersed, which suggests pre-existing digital consumption habits mattered more than geography alone. More importantly, top users were organizations rather than individuals. This is divergent from Twitter-based studies, where individuals are usually the top users. Even so, these organizations were diverse in their nature. Gender- and fashion-related activism pages, memegroups, and in particular, the international production and following of news collectives stood out, generating solidarity across borders.

Our study has some limitations. Since our monitoring is done daily at specific times, there may be biases toward the content of individual accounts. It is also impossible to tell how Instagram's filtering algorithm works as well. For instance, we observed posts by other celebrities were suppressed somewhat on the public page, and more likely to induce a more grassroots perception of the platform instead of reinforcing the presence of popular personas.

Overall, our research pushes the field forward in a few important ways. Our study confirms the observations from recent work, that show how memes, in their creation and dissemination, can spark instances of political participation. However, participation in these cases (such as Morocco) arises from an established movement, often targeted toward conversation. We show this form of 
visual communication - be it the memorializing of Mr. Floyd or enabling on ground protest during Black Out Tuesday — can be an effective call to action. Entertainers can get serious, and when they do, they can command the attention of an entire nation.

Moving forward, we hope to utilize this data to further understand the fine line between politics and entertainment, and what new media means for uplifting citizen journalism within democracies. 


\section{References}

Al-Kandari AJ, Al-Hunaiyyan AA and Al-Hajri R (2016) The influence of culture on Instagram use. Journal of Advances in Information Technology 7 (1): 54, 57.

Alicia G (2014) A Herstory of the\# BlackLivesMatter Movement. In: The Feminist Wire. Available at: https://thefeministwire.com/2014/10/blacklivesmatter-2/ (accessed May 23, 2021)

Anderson M, Barthel M, Perrin A, and Vogels EA (2020). \#BlackLivesMatter surges on Twitter after George Floyd's death. Report, Pew Center. June.

Arafa M and Armstrong C (2016) " Facebook to Mobilize, Twitter to Coordinate Protests, and YouTube to Tell the World": New Media, Cyberactivism, and the Arab Spring. Journal of Global Initiatives: Policy, Pedagogy, Perspective 10(1): pp.6.

Baptiste N (2021) The Mob at the Capitol Proves That Blue Lives Have Never Mattered to Trump Supporters. Mother Jones, January 8, 2021.

Bowenbank S (2020) "Instagram CEO Adam Mosseri Pledges to Amplify Black Voices After Shadow Banning Accusations.” Cosmopolitan, June 16, 2020.

Brown M, Ray R, Summers E and Fraistat N (2017) \# SayHerName: A case study of intersectional social media activism. Ethnic and Racial Studies 40(11): 1831-1846.

Buchanan L, Fessenden F, Lai KR, Park H, Parlapiano A, Tse A, Wallace T, Watkins D and Yourish, K (2015) What happened in Ferguson. The New York Times, 10, August 10, 2015.

Carney N (2016) All lives matter, but so does race: Black lives matter and the evolving role of social media. Humanity \& Society 40(2): 180-199.

Clayton DM (2018) Black lives matter and the civil rights movement: A comparative analysis of two social movements in the United States. Journal of Black Studies 49(5): 448-480.

Conover MD, Davis C, Ferrara E, McKelvey K, Menczer F, Flammini A. The geospatial characteristics of a social movement communication network. PloS one, $2013 \mathrm{Mar}$ 6;8(3):e55957.

Conover MD, Ferrara E, Menczer F, Flammini A. The digital evolution of occupy wall street. PloS one, 2013 May 29;8(5):e64679.

Corrigall-Brown C (2012) The power of pictures: Images of politics and protest. American Behavioral Scientist 56(2): 131-134.

Coscarelli J (2020) \#BlackoutTuesday: A Music Industry Protest Becomes a Social Media Moment. The New York Times, 2, June 02, 2020. 
Cortes MS (2020) "Black Creators React to TikTok's Apology and Share Experience of Suspected Shadowbanning." Refinery 29, June 5, 2020. https://www.refinery29.com/enus/2020/06/9853063/tiktok-black-lives-matter-content-censored-apology.

Edrington CL and Gallagher VJ (2019) Race and visibility: How and why visual images of black lives matter. Visual Communication Quarterly 26(4): 195-207.

Ferrara E, Chang H, Chen E, Muric G, and Patel J (2020). Characterizing social media manipulation in the 2020 US presidential election. First Monday.

Ferrara E, Varol O, Menczer F, Flammini A (2013). Traveling trends: social butterflies or frequent fliers?. In Proceedings of the first ACM conference on Online social networks pp. 213-222.

Ferrara E, Interdonato R, Tagarelli A. Online popularity and topical interests through the lens of instagram. InProceedings of the 25th ACM conference on Hypertext and social media 2014 Sep 1 (pp. 24-34).

Freelon D, Mcilwain CD and Clark M (2016) Beyond the hashtags: \#Ferguson, \#Blacklivesmatter, and the online struggle for offline justice. Center for Media and Social Impact. Report, American University, USA.

Freelon D, Bossetta M, Wells C, Lukito J, Xia Y, Adams K. Black trolls matter: Racial and ideological asymmetries in social media disinformation. Social Science Computer Review. 2020 Apr 7:0894439320914853.

Guynn J (2020) “Facebook while Black: Users Call It Getting 'Zucked,' Say Talking about Racism Is Censored as Hate Speech. USA Today, April 24, 2019.

Hariman R and Lucaites JL (2016) The public image: Photography and civic spectatorship. Chicago and London: University of Chicago Press.

Hermida A (2010) Twittering the news: The emergence of ambient journalism. Journalism practice, 4(3): 297-308.

Hermida A, Lewis SC and Zamith R (2014) Sourcing the Arab Spring: A case study of Andy Carvin's sources on Twitter during the Tunisian and Egyptian revolutions. Journal of computer-mediated communication 19(3): 479-499.

Hill E, Tiefenthäler A, Triebert C, Jordan D, Willis H and Stein R (2020) How George Floyd was killed in police custody. The New York Times, 31, May 31, 2020.

Hochman N and Manovich L (2013) Zooming into an Instagram City: Reading the local through social media. First Monday.

Howard PN and Hussain MM (2013) Democracy's fourth wave?: digital media and the Arab Spring. Oxford University Press. 
Hu Y, Manikonda L and Kambhampati S (2014) What we instagram: A first analysis of instagram photo content and user types. In Proceedings of the International AAAI Conference on Web and Social Media 2014 May 16 (Vol. 8, No. 1).

Jackson SJ (2016) (Re) imagining intersectional democracy from Black feminism to hashtag activism. Women's Studies in Communication 39(4): 375-379.

Jackson SJ, Bailey M and Welles BF (2020). \# HashtagActivism: Networks of race and gender justice. MIT Press.

Jacomy, M., Venturini, T., Heymann, S., \& Bastian, M. (2014). ForceAtlas2, a continuous graph layout algorithm for handy network visualization designed for the Gephi software. PloS one, 9(6), e98679.

Jang JY, Han K, Shih PC and Lee D (2015). Generation like: Comparative characteristics in instagram. In Proceedings of the 33rd Annual ACM Conference on Human Factors in Computing Systems 2015 Apr 18, pp. 4039-4042

Kaufman G. 'The Show Must Be Paused': What to Know About the Music Industry's Response to George Floyd's Death. Billboard, June 01, 2020.

Khondker HH (2011). Role of the new media in the Arab Spring. Globalizations, 8(5): 675-679.

Lee E, Lee JA, Moon JH and Sung Y (2015). Pictures speak louder than words: Motivations for using Instagram. Cyberpsychology, behavior, and social networking 18(9): 552-556.

Lopez G (2016) What were the 2014 Ferguson protests about? Vox, Jan 27, 2016.

Marsh WT (2018) Pictures Are Worth a Thousand Words: An Analysis of Visual Framing in Civil Rights and Black Lives Matter Protest Photography. PhD dissertation, Howard University.

McKelvey F, DeJong S, Frenzel J. Memes, scenes and \#ELXN2019s: How partisans make memes during elections. New Media \& Society. 2021 June.

Miles J (2013) Instagram power. McGraw-Hill Publishing.

Moreno-Almeida C. Memes as snapshots of participation: The role of digital amateur activists in authoritarian regimes. New Media \& Society. 2020 Mar 18:14614448820912722.

Neumayer C and Rossi L (2018) Images of protest in social media: Struggle over visibility and visual narratives. New Media \& Society 20(11): 4293-4310.

Papacharissi Z (2002) The virtual sphere: The internet as a public sphere. New media \& society: 4(1): 9-27.

Ray R (2020) Setting the record straight on the Movement for Black Lives. Ethnic and Racial Studies, 43(8): 1393-1401. 
Richardson, AV (2020b) The New Protest \#Journalism: Black Witnessing as Counternarrative. In: Bearing Witness While Black. Oxford University Press, pp. 45-72.

Solomon J, Kaplan D and Hancock LE (2021) Expressions of American White Ethnonationalism in Support for "Blue Lives Matter". Geopolitics, 26(3): 946-966.

Speltz M (2016) How photographs define the Civil Rights and Black Lives Matter movements. Time.

Theoharis J (2016) MLK would never shut down a freeway, and 6 other myths about the Civil Rights Movement and Black Lives Matter. The Root.

Theocharis Y, Lowe W, Deth JWV and García-Albacete G. (2015) Using Twitter to mobilize protest action: online mobilization patterns and action repertoires in the Occupy Wall Street, Indignados, and Aganaktismenoi movements. Information, Communication \& Society 18(2): 202-220.

Varol O, Ferrara E, Ogan CL, Menczer F, Flammini A. Evolution of online user behavior during a social upheaval. In Proceedings of the 2014 ACM conference on Web science 2014 Jun 23 (pp. 81-90).

Zauner C (2010) Implementation and benchmarking of perceptual image hash functions. $\mathrm{PhD}$ Thesis, University of Applied Sciences Upper Austria.

Zidani S, Moran R. Memes and the Spread of Misinformation: Establishing the Importance of Media Literacy in the Era of Information Disorder. Teaching Media Quarterly. 2021 May $28 ; 9(1)$.

${ }^{\mathrm{i}} \mathrm{https}: / / \mathrm{www} \cdot$ instagram.com/p/CA05yLDpDox/ 